Int. J. Dev. Biol. 57: 357-364 (2013)

doi: 10.1387/ijdb.130051ji

\title{
SMYD2 is induced during cell differentiation and participates in early development
}

\author{
BORJA SESÉ ${ }^{1}$, MARIA J. BARRERO ${ }^{1}$, MARIA-CARME FABREGAT ${ }^{1}$, \\ VERONIKA SANDER ${ }^{1}$ and JUAN CARLOS IZPISUA BELMONTE*,1,2 \\ ${ }^{1}$ Center for Regenerative Medicine in Barcelona, Barcelona, Spain and \\ ${ }^{2}$ Salk Institute for Biological Studies, La Jolla, CA, USA
}

\begin{abstract}
Histone modifying enzymes play critical roles in cell differentiation and development. In this study, we report that SMYD2 (SET and MYND domain containing protein 2), a histone lysine methyltransferase, is induced during human embryonic stem (ES) cell differentiation and it is preferentially expressed in somatic cells versus pluripotent cells. Knockdown of SMYD2 in human ES cells promotes the induction of endodermal markers during differentiation, while overexpression has opposite effects. In vivo experiments in zebrafish revealed that knockdown of smyd2a (a homologue gene of human SMYD2) causes developmental delay and aberrant tail formation, which is coincident with low expression of $\boldsymbol{n t l}$ and over induction Nodal-related genes during gastrulation. Taken together, these findings suggest that SMYD2 plays a critical role at early stages of development and in human ES cell differentiation.
\end{abstract}

KEY WORDS: SMYD2, differentiation, development, stem cell, methyltransferase

\section{Introduction}

Embryonic stem (ES) cells are characterized by their ability to self-renew indefinitely in vitro maintaining their undifferentiated state, and the capacity to give rise to any cell type in the body (Thomson et al., 1998). The molecular mechanisms underlying ES cells identity and their potential for differentiation are still poorly understood (Boyer et al., 2005, Niwa, 2007). During the last years, post-translational covalent modifications of histone proteins have emerged as a crucial epigenetic event to regulate the pluripotent state of ES cells and to establish cell fate decisions (Bibikova et al., 2008, Goldberg et al., 2007, Meissner, 2010). Histone modifications help to define chromatin structure and can be associated with active marks, offering accessible DNA for transcription, and repressive marks, where DNA is more packaged and inaccessible (Cheung and Lau, 2005, Kouzarides, 2007). One particular property of ES cells is that many developmental genes present both active H3K4 and repressive $\mathrm{H} 3 \mathrm{~K} 27$ methylation on their regulatory regions, the so-called "bivalent domains" (Azuara et al., 2006, Bernstein et al., 2006). This bivalency keeps these genes silenced in ES cells, but "poised" to become activated by losing the repressive mark, or kept silenced by removal of active marks during differentiation (Spivakov and Fisher, 2007).

In order to select candidates of histone modifying enzymes involved in pluripotency and differentiation of human ES cells, we identified a group of histone lysine demethylases and methyltransferases differentially expressed between undifferentiated and differentiated human ES cells (data not shown). Among them, SMYD2 emerged as a potential candidate due to its barely expression in undifferentiated human ES cells and later up-regulation after 30 days of differentiation towards the three germ layers. The SMYD (SET and MYND domain) protein family presents methyltransferase activity provided by its SET domain, which is split into two segments by its MYND domain, responsible for protein-protein interactions (Brown et al., 2006). In human, there are five members in the SMYD protein family (SMYD1-5) and have been shown to participate regulating gene transcription and cell proliferation. SMYD1 is a heart and muscle specific histone methyltransferase involved in cardiomyocyte and myogenic differentiation (Gottlieb et al., 2002, Li et al., 2009). The lack of Smyd1 in mice development results in embryonic death due to cardiac defects (Gottlieb et al., 2002). Knockdown of smyd1a/b in zebrafish causes skeletal and cardiac muscle defects and presents a disrupted expression of myofibril organization (Tan et al., 2006), SMYD3 has been mainly

Abbreviations used in this paper: ChIP, chromatin immunoprecipitation; ES, embryonic stem (cell); MO, morpholino; SMYD, SET and MYND domain containing protein.

\footnotetext{
*Address correspondence to: Juan-Carlos Izpisua-Belmonte. Salk Institute for Biological Studies, La Jolla, CA, USA

Fax: +1 858453 2573. e-mail: belmonte@salk.edu - web: www.cmrb.eu 
related with cancer cell proliferation (Hamamoto et al., 2004). Several findings indicate that endogenous expression of SMYD3 is present at very high levels in hepatocellular, colon and breast carcinoma, and silencing through siRNAs have an inhibitory effect in cell growth (Hamamoto et al., 2004, Hamamoto et al., 2006). Similarly to smyd1a/b, smyd3 plays an important role in cardiac and skeletal muscle development in zebrafish (Fujii et al., 2011). In the other hand, SMYD4 is significantly reduced in tumor cells and its re-expression dramatically decreases cancer cell growth (Hu et al., 2009). Also, Drosophila SMYD4 homologue has been involved in muscle development (Thompson and Travers, 2008). Little is known so far about SMYD5. Unlike the rest of family members, SMYD5 does not present a C-terminal tetratrico peptide repeat (TPR) domain (Abu-Farha et al., 2011).

SMYD2 was first described as a histone lysine methyltransferase mainly expressed in heart and brain tissue, with specific catalytic activity for H3K36 dimethylation, a mark associated with actively transcribed genes (Brown et al., 2006). Moreover, SMYD2 was associated to interact with HDAC1 and the Sin3A repression complex (Brown et al., 2006). In yeast, there is evidence of a link between H3K36 methylation and the recruitment of a repressive Rpd3 (the prototypical yeast HDAC) complex (Carrozza et al., 2005, Joshi and Struhl, 2005, Keogh et al., 2005). However, SMYD2 was also described to specifically monomethylate H3K4 in the presence of HSP90 $\alpha$ in vitro, with no activity for H3K36 (Abu-Farha et al., 2008). Despite observing a weak activity of H3K36 methylation in the absence of $\mathrm{HSP} 90 \alpha$, in vivo experiments suggested that H3K4 is the predominant site of methylation for SMYD2 (Abu-Farha et al., 2008). Regarding histone methylation, recent studies determined that SMYD2 also methylates histones $\mathrm{H} 2 \mathrm{~B}$ and $\mathrm{H} 4$ more efficiently than H3 in vitro (Wu et al., 2011). Further, several non-histone proteins have been identified as substrates for SMYD2 methylation such as p53 and retinoblastoma (Rb) (Cho et al., 2012, Huang et al., 2006, Jiang et al., 2011, Saddic et al., 2010, Scoumanne and Chen, 2008). Monomethylation of p53 at K370 reduces its binding ability to promoter target genes like p21 and mdm2, resulting in a decreased expression of these genes (Huang et al., 2006). Unexpectedly, adult hearts of Smyd2 conditional knockout mice showed no changes in p21 and mdm2 expression levels, and had no global effect in H3K36 or H3K4 methylation (Diehl et al., 2010). Additionally, Smyd2 was found dispensable for proper heart development in mouse (Diehl et al., 2010). Rb protein can be methylated by SMYD2 at K860 and facilitates its interaction with the methyl-binding protein L3MBTL1 (Saddic et al., 2010). More recently, SMYD2 was also found to methylate Rb at K810, which increases phosphorylation of Rb protein, and promotes cell cycle progression (Cho et al., 2012). In accordance with the effects observed on p53 and Rb tumour suppressors, a wide variety of

Fig. 1. Expression of SMYD family members during human embryonic stem (ES) cell differentiation. (A) mRNA levels of SMYD1-5 family members in human embryonic stem cells (ES[4] and ES[2]), induced pluripotent stem cells from human keratinocytes (KiPS4F1 and KiPS4F8), human fibroblasts (HF) and human keratinocytes (HEK). (B) mRNA levels of SMYD1-5 in ES[4] and ES[2] undifferentiated (dO) and at days 4, 8 and 15 of differentiation (C) mRNA levels of pluripotency-related genes during. ES[4] and ES[2] differentiation. Three independent differentiations were performed and one representative experiment is shown. Levels were determined by GPCR and normalized to GAPDH. Mean and standard deviation of triplicates are shown. human cancer showed high levels of SMYD2 expression (Cho et al., 2012, Komatsu et al., 2009). It was also reported that SMYD2 is involved in maintaining self-renewal activity of MLL-AF9-induced acute myeloid leukaemia (Zuber et al., 2011). Another novel nonhistone substrate for SMYD2, cytoplasmic HSP90, is methylated at K209 and K615 (Abu-Farha et al., 2011). In mouse, Smyd2 methylates HSP90 to form a complex with the sarcomeric protein titin to protect myocyte organization (Donlin et al., 2012, Voelkel et al., 2012). Here we reported the characterization of SMYD2 during human ES cell differentiation. Our data suggest that SMYD2 plays an important role during early differentiation events.

\section{Results}

\section{SMYD2 expression is strongly induced during human ES cell differentiation}

We first set up to analyze the potential differential expression of the SMYD family members in pluripotent and somatic cells by qPCR. mRNA levels of all five SMYD family members were measured in human embryonic stem (ES) cells (ES[2] and ES]4]), induced pluripotent (iPS) cells derived from human keratinocytes (KiPS) and human fibroblasts (HF) and keratinocytes (HEK) (Fig. 1A). Among all family members, SMYD2 clearly showed higher mRNA levels in somatic cells compared to pluripotent cells. We next tested the expression profile of the SMYD family members during the differentiation of human ES cells in the form of embryoid bodies (Fig. 1B). As expected, SMYD2 showed the most remark-
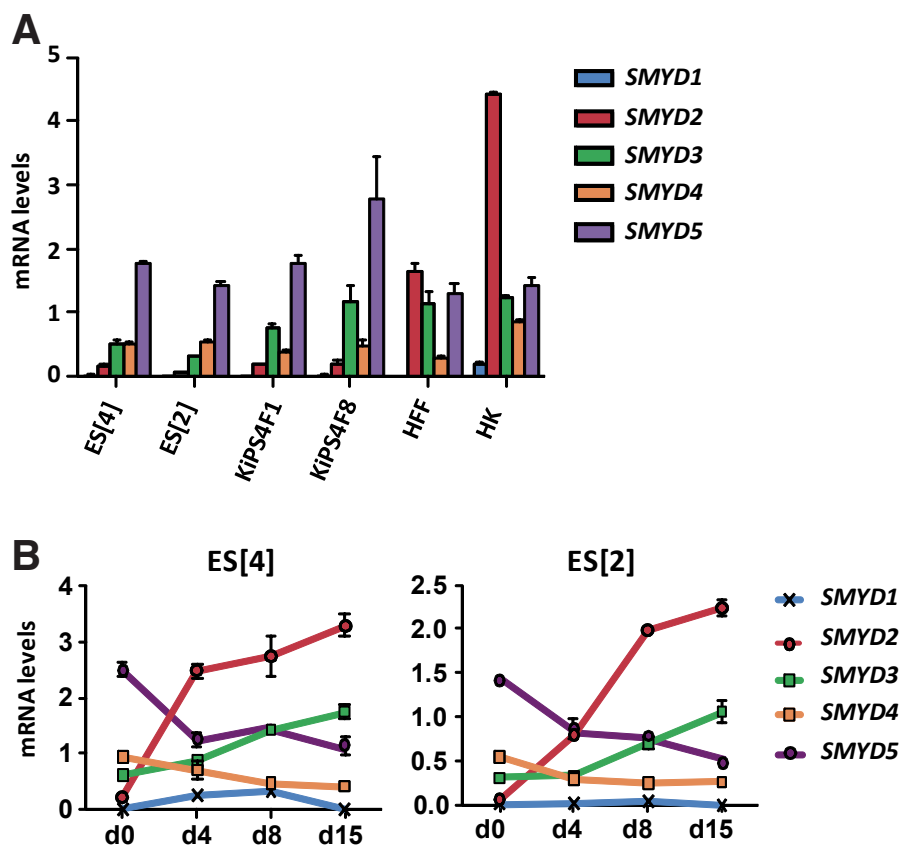

C
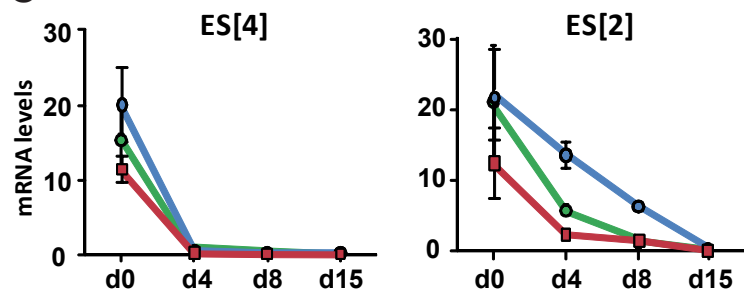
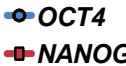

- SOX2 
able induction among the SMYD family members, which is coincident with the dowregulation of the expression of pluripotency-related genes (Fig. 1C). Taken together, our results show that SMYD2 is preferentially expressed in human somatic cells and induced during the differentiation of human pluripotent cells.

\section{SMYD2 promoter presents active chromatin marks in human ES cells}

Since SMYD2 is expressed at low levels in human ES cells but rapidly induced during differentiation we considered the potential presence of bivalent domains on its promoter in pluripotent cells. We performed ChIP assay to detect the presence of histone marks related with transcriptional activation (H3K4me) and repression (H3K27me) in ES[4] and ES[2] (Fig. 2). As a control, we tested the presence of histone marks for the pluripotency gene OCT4, and two well described genes containing bivalent domains in human ES cells, SOX17 and FOXA2. Despite being transcribed at low levels, SMYD2 showed remarkable levels of $\mathrm{H} 3 \mathrm{~K} 4 \mathrm{me} 2 / 3$ at its promoter. Levels of H3K27me3 showed variability between lines, being very low in ES[4] but significant in ES[2], while compared with the well known bivalent genes SOX17 and FOXA2. The presence of $\mathrm{H} 3 \mathrm{~K} 4 \mathrm{me} 2 / 3$ only at the SMYD2 promoter in ES[4] might suggest the existence of post-transcriptional mechanisms responsible for blocking its expression in human ES cells.

\section{The knockdown of SMYD2 promotes induction of endodermal genes during human ES cell differentiation}

To test if SMYD2 is plays a role in the differentiation of human ES cells we performed loss-of-function experiments. We generated lentiviral-transduced stable ES[4] cell lines expressing a shRNA against SMYD2(shSMYD2) (Huang et al., 2006) and a random non target shRNA (shControl). In self-renewing cells, the knockdown of SMYD2 did not show any morphological differences compared to the control, neither differences regarding the expression of selected pluripotency and differentiation genes (data not shown). However, during in vitro differentiation the SMYD2 knockdown line showed higher levels of endodermal genes (HNF4, FOXA2, SOX17) compared to the shControl line (Fig. 3A), but not significant differences in the induction of ectordermal $(P A X 6)$ or mesodermal (BRACHYURY) genes. The pluripotency-related genes OCT4, NANOG and SOX2 were similarly downregulated in the shSMYD2 and shControl lines. Our results suggest that SMYD2 might act as a negative regulator of endodermal differentiation.

\section{SMYD2 overexpression impairs proper differentiation of hu- man ES cells}

To further confirm the involvement of SMYD2 in differentiation we generated stable ES[4] cell lines stably overexpressing SMYD2 (SMYD2) or GFP as a control (GFP). The overexpression of SMYD2 in self-renewing cells did not cause significant morphological differences neither differences in the expression of selected pluripotency and differentiation genes compared to the control (Fig. 3B). Contrary to the knockdown, cells overexpressing SMYD2 showed a reduced induction of endodermal and mesodermal genes compared to the control line during differentiation (Fig. 3B). However, the ectodermal gene PAX6 was more induced in SMYD2 overexpressing cells than control cells. No differences
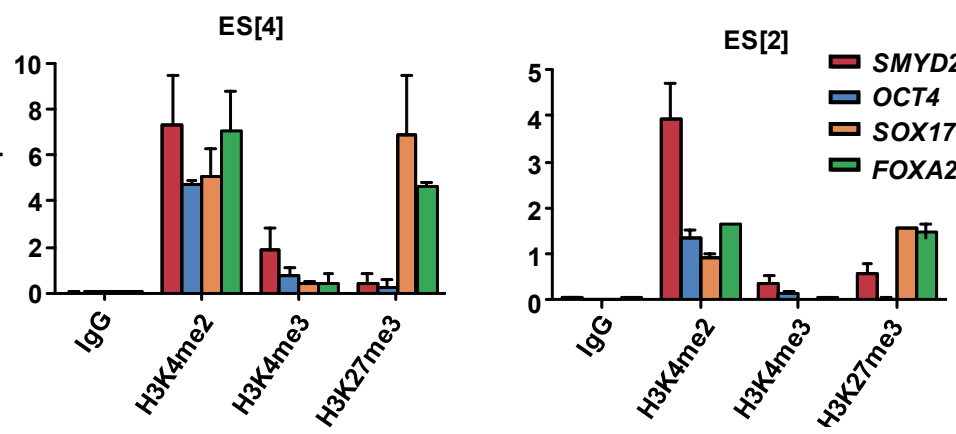

Fig. 2. Analysis of histone methylation marks in the SMYD2 promoter. ChIP assays using antibodies against H3K4me2, H3K4me3 and H3K27me3 in ES[4] and S[2]. The presence of the indicated gene regulatory regions in the immunoprecipitated chromatin was analyzed by GPCR. Values are represented as percentage of input. Mean and standard deviation corresponding to three independent experients are shown.

were detected between the SMYD2 and GFP overexpressing cell lines regarding the silencing of pluripotency genes during differentiation. These results confirm that SMYD2 acts as a repressor of endodermal genes and has no effect in the downregulation of pluripotency genes during human ES differentiation.

\section{The knockdown of smyd2a in zebrafish results in tail forma- tion defects}

To assess the effect of SMYD2 at early stages of development we performed knockdown experiments in zebrafish as in vivomodel. The zebrafish presents two homologous genes of smyd2a and $s m y d 2 b$. We first quantified the mRNA levels of both genes during zebrafish development from 0.2 to 48 hours post-fertilization (hpf) (Fig. 4A). Interestingly, smyd2a was maternally expressed, rapidly degraded after fertilization and induced again during gastrulation (5 to $10 \mathrm{hpf}$ ). smyd2b expression levels remained low until $10 \mathrm{hpf}$ and was dramatically induced after gastrulation. The induction of smyd2a during gastrulation suggests a potential role in germ layer specification. To confirm our hypothesis we designed a spliceblocking morpholino (smyd2a-MO) at the exon 1-intron 1 junction, to block proper splicing of the zygotic transcripts without affecting the maternal mRNA (Fig. 4B, upper panel). Zebrafish embryos were injected at one-cell stage with smyd2a-MO and a standardcontrol morpholino (Control-MO). As expected, the mature mRNA of smyd2awas undetectable in embryos injected with smyd2a-MO at $24 \mathrm{hpf}$ compared to embryos injected with Control-MO, while smyd2b expression was unaffected by the injection of smyd2a-MO (Fig. 4B, lower panel). Injected embryos were examined morphologically up to 6 days after injection (Fig. 4C). At 5 hpf, smyd2a-MO injected embryos could not be morphologically distinguished from the controls. At $24 \mathrm{hpf}$, we could detect some smyd2a morphant embryos with a tail defect (mild), and some others with a strong delay in development (severe). At $48 \mathrm{hpf}$, we could observe several degrees of tail defects, including a morphant phenotype with a complete absence of the tail (very severe). Later on, at 6 days after injection, all three smyd2a morphant phenotypes were distinguishable. To further confirm the specificity of smyd2a-MO effect, we performed a rescue experiment by co-injecting with in vitro-transcribed human SMYD2 mRNA (smyd2a-MO + SMYD2 mRNA) and evaluated the percentage embryos with different phenotypes at $24 \mathrm{~h}$ post-injection (Fig. 4D). Table 1 shows that 
co-injection of smyd2a-MO with human SMYD2 mRNA rescues both mortality (from 57\% to $36 \%$ ) and morphology (from $25 \%$ mild and $60 \%$ severe phenotype to $11 \%$ mild and $18 \%$ severe phenotype). Co-injection of human SMYD2 mRNA and Control-MO had no effects on mortality or phenotype compared to the injection of Control-MO alone. Therefore, the effects of smyd2a knockdown in zebrafish development appear specific.

\section{smyd2a knockdown in zebrafish affects the expression of genes involved in the Nodal pathway}

To gain insights into the potential pathways affected by the smyd2a knockdown we investigated the expression pattern of the T-box gene no tail (nt), a zebrafish Brachyury ortholog required for the formation of mesoderm and essential for tail development (Halpern et al., 1993, Schulte-Merker et al., 1994), by whole-mount in situhybridization (ISH) on embryos at $6 \mathrm{hpf}$ (Fig. 5A). As expected, all control embryos showed $n t$ expression at the margin cells as gastrulation proceeds. In contrast, most smyd2a-MO injected embryos showed altered pattern of $n t /$ expression characterized by either a reduction (35\% of embryos) or complete absence of $n t$ expression (53\% of embryos). Moreover, the ratio of the three different $n t$ expression patters in smyd2a morphants is similar to the percentages of different phenotypes at $24 \mathrm{hpf}$ (Fig. 4D, Table 1). To further identify specific transcripts affected by smyd2a knockdown, we analyzed the expression profile of a set of genes involved in gastrulation from $4 \mathrm{hpf}$ to $10 \mathrm{hpf}$ by qPCR (Fig. 5B). Nodal-related genes (chd, gsc, bon and cas) were up-regulated in the smyd2a-MO compared to the Control-MO. In addition to their strong induction, gsc and bon presented also a different profile of expression as they were still present at high levels even at $8 \mathrm{hpf}$, while the control-MO injected embryos had already reduced their expression levels. bmp2a and $\beta$-catenin- 1 are unaffected by smyd2a knockdown, suggesting that genes of the Bmp2 and Wnt pathways remain unaffected. These results indicate that smyd2a knockdown causes an induction of Nodal-target genes chd, gsc, bon and cas during gastrulation events in zebrafish.

\section{Discussion}

In this work we show that SMYD2 is involved in human ES cell differentiation. SMYD2 is expressed at high levels in somatic cells compared with pluripotent cells, whereas the rest of family members are not so differentially expressed. During human ES cell differentiation, SMYD2 is also the most induced family member. SMYD1 and 3, which share the highest degree of sequence homology with SMYD2 (Abu-Farha et al., 2011), are also induced but not so remarkably. SMYD3 present a progressive induction but only around 3-fold change compared with undifferentiated cells. Even at low levels, SMYD1 was induced during differentiation reaching its peak of expression at day 8 . This indicates that SMYD1 might be involved also in early development, consistent with previous studies involving Smyd1 in mouse developing heart

Fig 3. Gain-and-loss of function of SMYD2 during human embryonic stem (ES) cell differentiation. (A) mRNA levels of the indicated genes during the in vitro differentiation of SMYD2 knockdown (shSMYD2) and control (shControl) ES[4] cell lines. (B) mRNA levels of the indicated genes during the in vitro differentiation of SMYD2 overexpressing (SMYD2) and control (GFP) ES[4] cell lines. mRNA levels were measured by GPCR at the indicated days of differentiation and normalized to GAPDH. One representative experiment out of three independent experiments is shown. Mean and standard deviation from triplicates are shown. 
TABLE 1

\section{SURVIVAL RATES AND PHENOTYPES OF MORPHOLINO INJECTIONS AND RESCUE EXPERIMENT AT 24 HPF}

\begin{tabular}{|c|c|c|c|c|c|c|}
\hline & n. & Dead (\%) & $\begin{array}{c}\text { No. } \\
\text { Surviving }\end{array}$ & $\begin{array}{c}\text { wild type } \\
\text { (\%) }\end{array}$ & mild (\%) & $\begin{array}{c}\text { severe } \\
(\%)\end{array}$ \\
\hline Control-MO & 339 & $9 \pm 3$ & 307 & $94 \pm 3$ & $6 \pm 3$ & $0 \pm 0$ \\
\hline smyd2a-MO & 545 & $57 \pm 3$ & 238 & $15 \pm 7$ & $25 \pm 5$ & $60 \pm 12$ \\
\hline smyd2a-MO + SMYD2 RNA & 665 & $36 \pm 9$ & 436 & $71 \pm 16$ & $11 \pm 4$ & $18 \pm 16$ \\
\hline Control-MO + SMYD2 RNA & 512 & $7 \pm 2$ & 475 & $97 \pm 3$ & $3 \pm 2$ & $0 \pm 0$ \\
\hline
\end{tabular}

Morpholino injections: Control-MO and smyd2a-MO;

Rescue experiments: smyd2a-MO + SMYD2 RNA and Control-MO + SMYD2 RNA

Mean and standard deviation from three independent experiments are shown.

as a direct target of MEF2C (Phan et al., 2005).

Given the low levels of expression of SMYD2 in pluripotent cells, we hypothesized the presence of bivalent domains on its promoter to keep it repressed. Unexpectedly, we found variable levels of H3K27me3 between cell lines. In ES[4] the SMYD2 promoter was marked with H3K4 methylation marks only, suggesting that SMYD2 expression could be blocked by an alternative mechanism. Recently, Lipchina et al., (Lipchina et al., 2011) identified SMYD2, together with other 145 genes, as a high-confidence target of the miR-302/367 cluster in human ES cells. miR-302/367 is expressed in undifferentiated conditions and is downregulated upon neuronal differentiation, releasing the expression of its target genes (Lipchina et al., 2011). Thus, a possible miR-302/367 regulation of SMYD2 might explain the low levels of expression in pluripotent cells.

The knockdown of SMYD2 promoted the induction of endodermal genes during human ES cell differentiation, whereas overexpression had opposite effects. We further investigated the effect of SMYD2 depletion in vivo using the zebrafish as a model. Our results show that both smyd2a and $s m y d 2 b$ were induced during development, and surprisingly, smyd2a was found to be maternally expressed in zebrafish embryos. Knockdown of smyd2a causes a delay in zebrafish development and tail deformities in more than $80 \%$ of surviving embryos at $24 \mathrm{hpf}$, whereas rescue experiments reduced the morphant phenotype to $30 \%$. The fact that we were able to rescue smyd2a morphant phenotype by co-injecting human SMYD2 mRNA suggests a very well conserved function of SMYD2 among species. Intriguingly, it was recently reported that smyd2a knockdown generates severe skeletal and cardiac muscle defects in zebrafish (Donlin et al., 2012, Voelkel et al., 2012). Regarding the cardiac phenotype, we did not appreciate any abnormalities, even in the very severe morphant phenotype at $6 \mathrm{dpf}$, consistent with mice conditional-knockout experiments where Smyd2 was dispensable for heart development (Diehl et al., 2010).

The smyd2a knockdown phenotype that we observe is characteristic of embryonic dorsalization and resembles the phenotype of $n t /$ mutant embryos (Odenthal et al., 1996). Accordingly, the observed
A

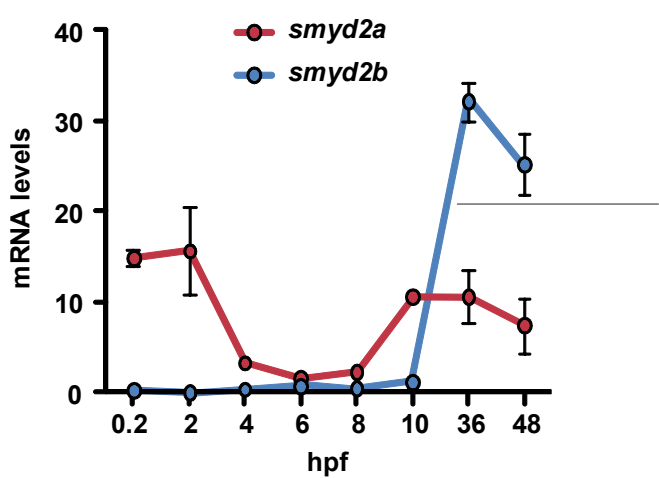

C

Control-MO smyd2a-MO

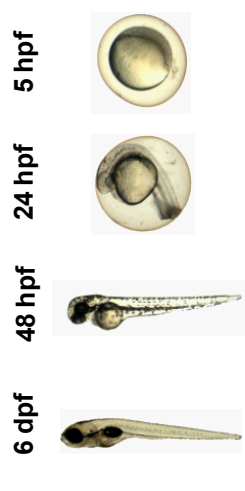

wild type
B

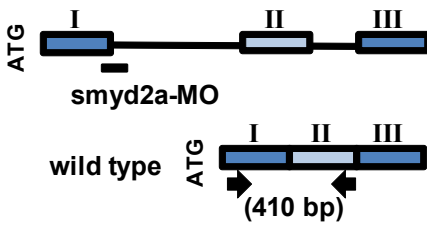

splice-
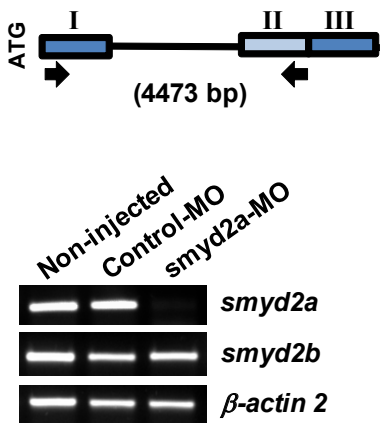

D

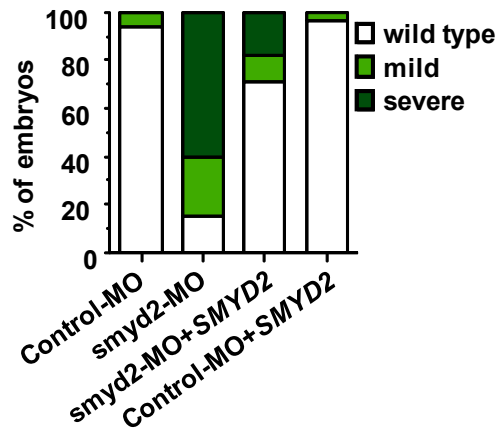

Fig 4. smyd2a knockdown in zebrafish development. (A) smyd2a and smyd2b mRNA levels at different hours post fer tilization (hpf). Levels were determined by QPCR and normalized to 18S. Two independent experiments were carried out and one representative experiment is shown. Mean and standard deviation from two independent quantifications are shown. (B) The upper panel shows a schematic representation of the spliceblocking morpholino smyd2a-MO at the exon1-intron 1 junction. Specific primers for smyd2a were designed at each side of exon 1 and intron 1 flanking a region of $410 \mathrm{bp}$ in wild type mRNA, and $4473 \mathrm{bp}$ in unspliced mRNA. Lower panel shows the absence of mature smyd2a mRNA at $24 \mathrm{hpf}$ in smyd2a-MO compared to Control-MO and non-injected embryos. Expression of smyd2b was unaffected by the smyd2a-MO injection. $\beta$-actin 2 was used as control. (C) Different phenotypes at 5, 24, $48 \mathrm{hpf}$ and 6 dpf of embryos injected with Control-MO and smyd2a-MO. (D) Percentage of phenotypes of morpholino injection (Control-MO and smyd2a-MO) and rescue experiment (smyd2a-MO + SMYD2 mRNA and Control-MO + SMYD2 $m R N A)$ at $24 \mathrm{hpf}$. Means from three independent experiments are shown. 
dorsalization effects were consistent with reduced or absent levels of $n t /$ transcript at $6 \mathrm{hpf}$. On the contrary, knockdown of SMYD2 in human ES cell differentiation did not affect the expression of the $n t$ ortholog, BRACHYURY(Fig. 3A). This discrepancy might be caused by the differences between the two model systems or to the lower efficiency of SMYD2 knockdown in ES cells. Wealso observed increased expression levels of Nodal-related genes, such as bon and cas, described to promote the formation of endoderm in zebrafish (Reiter et al., 2001, Stainier, 2002). Also, in Xenopus, goosecoid and Mix.1, the homologous genes of $g s c$ and bon respectively, act together to promote endodermal differentiation and suppress expression of mesodermal Xbra, the $n t /$ homologous gene (Latinkic and Smith, 1999). Eventually, high levels of gsc and bon at 6 and 8 hpf in smyd2a-MO embryos might have repressive effects over mesoderm induction. Overall, the zebrafish phenotype seems consistent with the induction of endodermal genes in the knockdown of SMYD2 during human ES cell differentiation.

Since, SMYD2 has been previously involved in transcriptional activation through monomethylation of H3K4 we speculate that it might participate in the induction of repressors of the endodermal fate. Alternatively, it might act as a transcriptional repressor itself through its association with $\mathrm{HDACl}$ and Sin3a repression complexes (Brown et al., 2006). However, methylation of non-histone targets might also account for these effects. For example, recent findings indicate that p53 knockdown causes a delay in differentiation of human ES cells, and ectopic expression of $\mathrm{p} 53 \mathrm{R} 175 \mathrm{H}$, a mutated inactive form of $\mathrm{p} 53$, failed to induce differentiation (Jain et al., 2012).

In summary, our study shows that SMYD2 is expressed at low levels in pluripotent cells but is strongly induced during differentiation. Knockdown of SMYD2 induced expression of endodermal genes, whereas overexpression leads to a blockade of differentiation by impairing induction of most of differentiation genes. Moreover, in vivo experiments in the zebrafish showed that smyd2ais involved in mesoderm formation and has a critical role from very early stages during development. In conclusion, our work suggests that SMYD2 plays an early decisive role in embryonic differentiation.

\section{Materials and Methods}

\section{Cell culture and differentiation}

Human embryonic stem cell lines ES[4] and ES[2] (Raya et al., 2008), were grown on matrigel-coated plates in irradiated mouse embryonic fibroblasts conditioned HES media (Knock out DMEM, 20\% Knock out serum replacement, nonessential amino acids, $2 \mathrm{mML}$-glutamine and $50 \mu \mathrm{M}$ $\beta$-mercaptoethanol) and supplemented with $10 \mathrm{ng} / \mathrm{ml} \mathrm{FGF}$.

For in vitro differentiation, cells were trypsinized into a single cell suspension and resuspended in MEF-conditioned HES media. Embryoid body (EB) formation was induced by seeding 100,000 cells in each well of 96-well v-bottom, low attachment plates and centrifuging the plates at 950 $\mathrm{g}$ for $5 \mathrm{~min}$ to aggregate the cells. After 3 days the embryoid bodies were transferred to $0.1 \%$ gelatin-coated dishes and cultured in differentiation medium (Knock out DMEM, 20\% fetal bovine serum, nonessential amino acids, $2 \mathrm{mM}$ L-glutamine and $50 \mu \mathrm{M} \beta$-mercaptoethanol) up to 15 days.
B

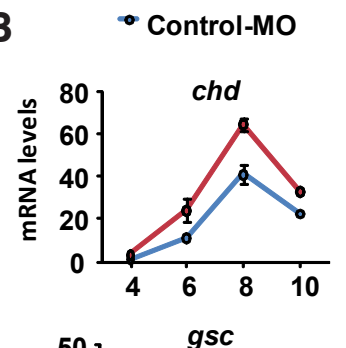

- smyd2a-MO
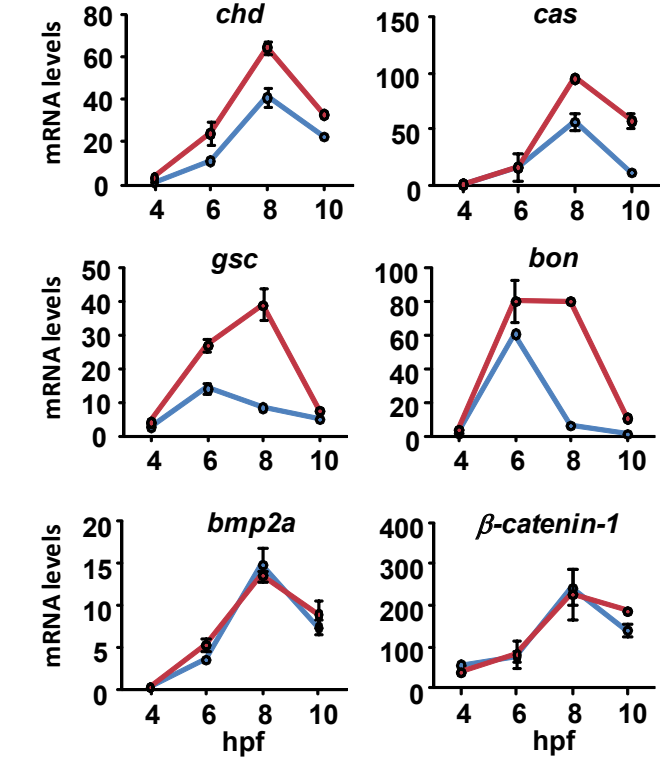

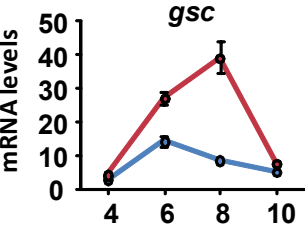

$9 / 17$

$6 / 17$

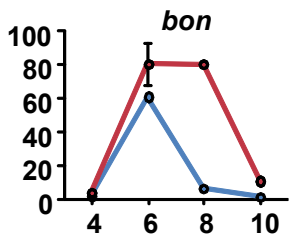

$2 / 17$

.

Fig. 5. Effects of smyd2a knockdown on gene expression during zebrafish gastrulation. (A) In situ hybridization of $n t l$ in Control-MO and smyd2a-MO injected embryos at 6 hpf. Embryos shown in lateral views (left), and animal pole views (right). (B) mRNA levels of indicated genes in Control-MO and smyd2a-MO embryos at 4, 6, 8, and 10 hpf. 50 embryos were collected at each point. Mean and standard deviation of triplicate quantifications are shown.

\section{RNA extraction and $q P C R$}

RNA was extracted using TRIZOL (Invitrogen) and CDNA synthesis was performed using the Cloned AMV First-Strand cDNA Synthesis Kit (Invitrogen). Quantification of mRNA levels was carried out by real time PCR using SYBER Green. qPCR levels were normalized to GAPDH in human cells and to $18 S$ in zebrafish.

\section{ChIP assays}

Chromatin immunoprecipitation (ChIP) assays were performed according to Adamo et al., (Adamo et al., 2011). The antibodies used were antiH3K4me2 (07030 from Millipore), H3K4me3 (07-473 from Millipore), and H3K27me3 (07-449 from Millipore). Purified chromatin was quantified using qPCR. The sequences of the oligonucleotides are available on request.

\section{Lentiviral production and infection}

Previously described short hairpin against SMYD2 (Huang et al., 2006) and a non target short hairpin were cloned into the lentiviral PLVTHM vector (Addgene plasmid 12247). Virus production was performed as described (Wiznerowicz and Trono, 2003). After infection, GFP positive cells were selected by FACS sorting.

\section{Vector construction and transfection}

Flag-tagged SMYD2 cDNA was cloned into vector pTP6 (Pratt et al., 2000). ES[4] were transfected with linearized pTP6-SMYD2 and pTP6 empty vector and clones were selected with $2 \mathrm{ug} / \mathrm{ml}$ puromycin and pooled. SMYD2 expression was confirmed by qPCR and western blot.

\section{Zebrafish microinjection of morpholino and SMYD2 mRNA}

Antisense morpholino-oligonucleotides (MO) were supplied by Gene Tools LCC (Philomath, OR). The sequence of smyd2a splice-blocking MO (smyd2a-MO) is 5' TTATAAGGAGCGCTGACCTGGTAAA 3' and was designed to block smyd2a proper splicing by binding to the splice site located between exon 1 and intron 1. The sequence of the standard control MO (Control-MO) was 5' CCTCTTACCTCAGTTACAATTTATA 3' and was 
used as an injection control. MOs were diluted in Danieau buffer to a final concentration of $0.35 \mathrm{mM}$ and were injected at 1-2 cell stage of fertilized wild-type zebrafish ( $A B$ strain) eggs using microinjector. Flag-tagged SMYD2 cDNA was cloned into pCS2 vector for mRNA synthesis using the mMESSAGE mMACHINE kit (Ambion, AMI344, Life Technologies, USA) following the manufacturer's instructions. Rescue experiments were performed by co-injecting $30 \mathrm{pg}$ of synthesized SMYD2 mRNA with $0.35 \mathrm{mM}$ of smyd2a-MO or Control-MO.

\section{Whole mount in situ hybridization}

Antisense ntl RNA probe was synthesized using the DIG RNA Labeling Kit SP6/T7 (Roche). Embryos were collected and fixed at $6 \mathrm{hpf}$. Whole mount in situ hybridization was performed as previously described (Jopling et al., 2010).

\section{Acknowledgments}

B.S. was a recipient of a FPU predoctoral fellowship from MICINN. M.J.B was partially supported by the Ramón y Cajal program and MICINN grants RYC-2007-01510 and SAF2009-08588. This work was supported by grants from the G. Harold and Leila Y. Mathers Charitable Foundation, The Leona M. and Harry B. Helmsley Charitable Trust, TERCEL-ISCIIIMINECO, CIBER and Fundacion Cellex to J.C.I.B.

\section{References}

ABU-FARHA, M., LAMBERT, J.P., AL-MADHOUN, A.S., ELISMA, F., SKERJANC, I.S. and FIGEYS, D. (2008). The tale of two domains: proteomics and genomics analysis of SMYD2, a new histone methyltransferase. Mol Cell Proteomics 7: 560-572.

ABU-FARHA, M., LANOUETTE, S., ELISMA, F., TREMBLAY, V., BUTSON, J., FIGEYS, D. and COUTURE, J.F. (2011). Proteomic analyses of the SMYD family interactomes identify HSP90 as a novel target for SMYD2. J Mol Cell Biol 3: 301-308.

ADAMO, A., SESE, B., BOUE, S., CASTANO, J., PARAMONOV, I., BARRERO, M.J. and IZPISUA BELMONTE, J.C. (2011). LSD1 regulates the balance between self-renewal and differentiation in human embryonic stem cells. Nat Cell Biol 13: 652-659.

AZUARA, V., PERRY, P., SAUER, S., SPIVAKOV, M., JORGENSEN, H.F., JOHN, R.M., GOUTI, M., CASANOVA, M., WARNES, G., MERKENSCHLAGER, M. et al., (2006). Chromatin signatures of pluripotent cell lines. Nat Cell Bio/8: 532-538.

BERNSTEIN, B.E., MIKKELSEN, T.S., XIE, X., KAMAL, M., HUEBERT, D.J., CUFF, J., FRY, B., MEISSNER, A., WERNIG, M., PLATH, K. et al., (2006). A bivalent chromatin structure marks key developmental genes in embryonic stem cells. Cell 125: 315-326.

BIBIKOVA, M., LAURENT, L.C., REN, B., LORING, J.F. and FAN, J.B. (2008). Unraveling epigenetic regulation in embryonic stem cells. Cell Stem Cell 2: 123-134.

BOYER, L.A., LEE, T.I., COLE, M.F., JOHNSTONE, S.E., LEVINE, S.S., ZUCKER, J.P., GUENTHER, M.G., KUMAR, R.M., MURRAY, H.L., JENNER, R.G. et al., (2005). Core transcriptional regulatory circuitry in human embryonic stem cells. Cell 122: 947-956.

BROWN, M.A., SIMS, R.J., 3RD, GOTTLIEB, P.D. and TUCKER, P.W. (2006). Identification and characterization of Smyd2: a split SET/MYND domain-containing histone $\mathrm{H} 3$ lysine 36 -specific methyltransferase that interacts with the $\mathrm{Sin} 3$ histone deacetylase complex. Mol Cancer 5: 26.

CARROZZA, M.J., LI, B., FLORENS, L., SUGANUMA, T., SWANSON, S.K., LEE, K.K., SHIA, W.J., ANDERSON, S., YATES, J., WASHBURN, M.P. et al., (2005), Histone $\mathrm{H} 3$ methylation by Set2 directs deacetylation of coding regions by Rpd3S to suppress spurious intragenic transcription. Cell 123: 581-592.

CHEUNG, P. and LAU, P. (2005). Epigenetic regulation by histone methylation and histone variants. Mol Endocrinol 19: 563-573.

CHO, H.S., HAYAMI, S., TOYOKAWA, G., MAEJIMA, K., YAMANE, Y., SUZUKI, T., DOHMAE, N., KOGURE, M., KANG, D., NEAL, D.E. et al., (2012). RB1 methylation by SMYD2 enhances cell cycle progression through an increase of RB1 phosphorylation. Neoplasia 14: 476-486.

DIEHL, F., BROWN, M.A., VAN AMERONGEN, M.J., NOVOYATLEVA, T., WIETELMANN, A., HARRISS, J., FERRAZZI, F., BOTTGER, T., HARVEY, R.P., TUCKER, P.W. et al., (2010). Cardiac deletion of Smyd2 is dispensable for mouse heart development. PLoS One 5: e9748.

DONLIN, L.T., ANDRESEN, C., JUST, S., RUDENSKY, E., PAPPAS, C.T., KRUGER, M., JACOBS, E.Y., UNGER, A., ZIESENISS, A., DOBENECKER, M.W. et al., (2012). Smyd2 controls cytoplasmic lysine methylation of $\mathrm{Hsp} 90$ and myofilament organization. Genes Dev 26: 114-119.

FUJII, T., TSUNESUMI, S., YAMAGUCHI, K., WATANABE, S. and FURUKAWA, Y. (2011). Smyd3 is required for the development of cardiac and skeletal muscle in zebrafish. PLoS One 6: e23491.

GOLDBERG, A.D., ALLIS, C.D. and BERNSTEIN, E. (2007). Epigenetics: alandscape takes shape. Cell 128: 635-638.

GOTTLIEB, P.D., PIERCE, S.A., SIMS, R.J., YAMAGISHI, H., WEIHE, E.K., HARRISS, J.V., MAIKA, S.D., KUZIEL, W.A., KING, H.L., OLSON, E.N. et al., (2002). Bop encodes a muscle-restricted protein containing MYND and SET domains and is essential for cardiac differentiation and morphogenesis. Nat Genet 31: 25-32.

HALPERN, M.E., HO, R.K., WALKER, C. and KIMMEL, C.B. (1993). Induction of muscle pioneers and floor plate is distinguished by the zebrafish no tail mutation. Cell 75: 99-111.

HAMAMOTO, R., FURUKAWA, Y., MORITA, M., IIMURA, Y., SILVA, F.P., LI, M., YAGYU, R. and NAKAMURA, Y. (2004). SMYD3 encodes a histone methyltransferase involved in the proliferation of cancer cells. Nat Cell Biol 6: 731-740.

HAMAMOTO, R., SILVA, F.P., TSUGE, M., NISHIDATE, T., KATAGIRI, T., NAKAMURA, Y. and FURUKAWA, Y. (2006). Enhanced SMYD3 expression is essential for the growth of breast cancer cells. Cancer Sci 97: 113-118.

HU, L., ZHU, Y.T., QI, C. and ZHU, Y.J. (2009). Identification of Smyd4 as a potential tumor suppressor gene involved in breast cancer development. Cancer Res 69: 4067-4072.

HUANG, J., PEREZ-BURGOS, L., PLACEK, B.J., SENGUPTA, R., RICHTER, M., DORSEY, J.A., KUBICEK, S., OPRAVIL, S., JENUWEIN, T. and BERGER, S.L. (2006). Repression of p53 activity by Smyd2-mediated methylation. Nature 444: 629-632.

JAIN, A.K., ALLTON, K., IACOVINO, M., MAHEN, E., MILCZAREK, R.J., ZWAKA, T.P., KYBA, M. and BARTON, M.C. (2012). p53 regulates cell cycle and microRNAs to promote differentiation of human embryonic stem cells. PLOS Biol 10: e1001268.

JIANG, Y., SIRINUPONG, N., BRUNZELLE, J. and YANG, Z. (2011). Crystal structures of histone and p53 methyltransferase SmyD2 reveal a conformational flexibility of the autoinhibitory C-terminal domain. PLoS One 6: e21640.

JOPLING, C., SLEEP, E., RAYA, M., MARTI, M., RAYA, A. and IZPISUABELMONTE, J.C. (2010). Zebrafish heart regeneration occurs by cardiomyocyte dedifferentiation and proliferation. Nature 464: 606-609.

JOSHI, A.A. and STRUHL, K. (2005). Eaf3 chromodomain interaction with methylated H3-K36 links histone deacetylation to Pol II elongation. Mol Cell 20: 971-978.

KEOGH, M.C., KURDISTANI, S.K., MORRIS, S.A., AHN, S.H., PODOLNY, V., COLLINS, S.R., SCHULDINER, M., CHIN, K., PUNNA, T., THOMPSON, N.J. et al., (2005). Cotranscriptional set2 methylation of histone $\mathrm{H} 3$ lysine 36 recruits a repressive Rpd3 complex. Cell 123: 593-605.

KOMATSU, S., IMOTO, I., TSUDA, H., KOZAKI, K.I., MURAMATSU, T., SHIMADA, Y., AIKO, S., YOSHIZUMI, Y., ICHIKAWA, D., OTSUJI, E. et al., (2009). Overexpression of SMYD2 relates to tumor cell proliferation and malignant outcome of esophageal squamous cell carcinoma. Carcinogenesis 30: 1139-1146.

KOUZARIDES, T. (2007). Chromatin modifications and their function. Cell128:693-705.

LATINKIC, B.V. and SMITH, J.C. (1999). Goosecoid and mix.1 repress Brachyury expression and are required for head formation in Xenopus. Development 126: 1769-1779.

LI, D., NIU, Z., YU, W., QIAN, Y., WANG, Q., LI, Q., YI, Z., LUO, J., WU, X., WANG, Y. et al., (2009). SMYD1, the myogenic activator, is a direct target of serum response factor and myogenin. Nucleic Acids Res 37: 7059-7071.

LIPCHINA, I., ELKABETZ, Y., HAFNER, M., SHERIDAN, R., MIHAILOVIC, A., TUSCHL, T., SANDER, C., STUDER, L. and BETEL, D. (2011). Genome-wide identification of microRNA targets in human ES cells reveals a role for miR-302 in modulating BMP response. Genes Dev 25: 2173-2186.

MEISSNER, A. (2010). Epigenetic modifications in pluripotent and differentiated cells. Nat Biotechnol 28: 1079-1088.

NIWA, H. (2007). How is pluripotency determined and maintained? Development 134: 635-646.

ODENTHAL, J., HAFFTER, P., VOGELSANG, E., BRAND, M., VAN EEDEN, F.J., 


\section{B. Sesé et al.}

FURUTANI-SEIKI, M., GRANATO, M., HAMMERSCHMIDT, M., HEISENBERG, C.P., JIANG, Y.J. et al., (1996). Mutations affecting the formation of the notochord in the zebrafish, Danio rerio. Development 123: 103-115.

PHAN, D., RASMUSSEN, T.L., NAKAGAWA, O., MCANALLY, J., GOTTLIEB, P.D., TUCKER, P.W., RICHARDSON, J.A., BASSEL-DUBY, R. and OLSON, E.N. (2005). $\mathrm{BOP}$, a regulator of right ventricular heart development, is a direct transcriptional target of MEF2C in the developing heart. Development 132: 2669-2678.

PRATT, T., SHARP, L., NICHOLS, J., PRICE, D.J. and MASON, J.O. (2000). Embryonic stem cells and transgenic mice ubiquitously expressing a tau-tagged green fluorescent protein. Dev Biol 228: 19-28.

RAYA, A., RODRIGUEZ-PIZA, I., ARAN, B., CONSIGLIO, A., BARRI, P.N., VEIGA, A. and IZPISUA BELMONTE, J.C. (2008). Generation of cardiomyocytes from new human embryonic stem cell lines derived from poor-quality blastocysts. Cold Spring Harb Symp Quant Biol 73: 127-135.

REITER, J.F., KIKUCHI, Y. and STAINIER, D.Y. (2001). Multiple roles for Gata5 in zebrafish endoderm formation. Development 128: 125-135.

SADDIC, L.A., WEST, L.E., ASLANIAN, A., YATES, J.R., 3RD, RUBIN, S.M., GOZANI, O. and SAGE, J. (2010). Methylation of the retinoblastoma tumor suppressor by SMYD2. J Biol Chem 285: 37733-37740.

SCHULTE-MERKER, S., VAN EEDEN, F.J., HALPERN, M.E., KIMMEL, C.B. and NUSSLEIN-VOLHARD, C. (1994). no tail (ntl) is the zebrafish homologue of the mouse T (Brachyury) gene. Development 120: 1009-1015.

SCOUMANNE, A. and CHEN, X. (2008). Protein methylation: a new mechanism of p53 tumor suppressor regulation. Histol Histopathol 23: 1143-1149.

SPIVAKOV, M. and FISHER, A.G. (2007). Epigenetic signatures of stem-cell identity.
Nat Rev Genet 8: 263-271

STAINIER, D.Y. (2002). A glimpse into the molecular entrails of endoderm formation. Genes Dev 16: 893-907.

TAN, X., ROTLLANT, J., LI, H., DE DEYNE, P. and DU, S.J. (2006). SmyD1, a histone methyltransferase, is required for myofibril organization and muscle contraction in zebrafish embryos. Proc Natl Acad Sci USA 103: 2713-2718.

THOMPSON, E.C. and TRAVERS, A.A. (2008). A Drosophila Smyd4 homologue is a muscle-specific transcriptional modulator involved in development. PLOS One 3: e3008.

THOMSON, J.A., ITSKOVITZ-ELDOR, J., SHAPIRO, S.S., WAKNITZ, M.A., SWIERGIEL, J.J., MARSHALL, V.S. and JONES, J.M. (1998). Embryonic stem cell lines derived from human blastocysts. Science 282: 1145-1147.

VOELKEL, T., ANDRESEN, C., UNGER, A., JUST, S., ROTTBAUER, W. and LINKE, W.A. (2012). Lysine methyltransferase Smyd2 regulates Hsp90-mediated protection of the sarcomeric titin springs and cardiac function. Biochim Biophys Acta.

WIZNEROWICZ, M. and TRONO, D. (2003). Conditional suppression of cellulargenes: lentivirus vector-mediated drug-inducible RNAinterference. J Virol77: 8957-8961.

WU, J., CHEUNG, T., GRANDE, C., FERGUSON, A.D., ZHU, X., THERIAULT, K. CODE, E., BIRR, C., KEEN, N. and CHEN, H. (2011). Biochemical characterization of human SET and MYND domain-containing protein 2 methyltransferase. Biochemistry 50: 6488-6497.

ZUBER, J., RAPPAPORT, A.R., LUO, W., WANG, E., CHEN, C., VASEVA, A.V., SHI, J. WEISSMUELLER, S., FELLMANN, C., TAYLOR, M.J. et al., (2011). An integrated approach to dissecting oncogene addiction implicates a Myb-coordinated selfrenewal program as essential for leukemia maintenance. Genes Dev25: 1628-1640. 
Further Related Reading, published previously in the Int. J. Dev. Biol.

Retinoic acid stability in stem cell cultures

Kyle A. Sharow, Boris Temkin and Mary Ann Asson-Batres

Int. J. Dev. Biol. (2012) 56: 273-278

Expression analysis of the polypyrimidine tract binding protein (PTBP1) and its paralogs PTBP2 and PTBP3 during Xenopus tropicalis embryogenesis

Maud Noiret, Yann Audic and Serge Hardy

Int. J. Dev. Biol. (2012) 56: 747-753

Revisiting old vaginal topics: conversion of the Müllerian vagina and origin of the "sinus" vagina

Yi Cai

Int. J. Dev. Biol. (2009) 53: 925-934

Limb muscle development

Bodo Christ and Beate Brand-Saberi

Int. J. Dev. Biol. (2002) 46: 905-914

Mesonephric kidney--a stem cell factory?

$\mathrm{K}$ Sainio and A Raatikainen-Ahokas

Int. J. Dev. Biol. (1999) 43: 435-439

Towards a molecular anatomy of the Xenopus pronephric kidney

A W Brändli

Int. J. Dev. Biol. (1999) 43: 381-395

5 yr ISI Impact Factor $(2011)=2.959$

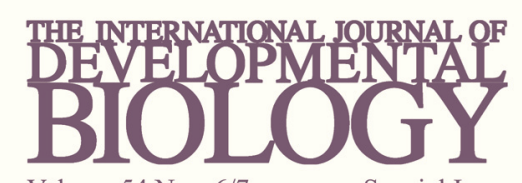

Volume 54 Nos. $6 / 7$

Special Issue
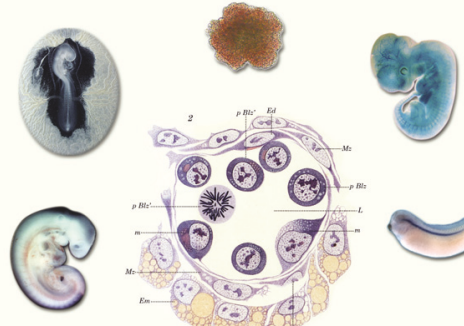

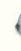
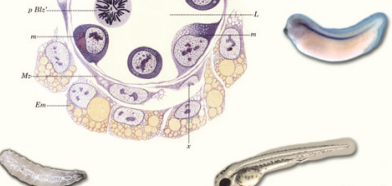

Developmental Hematopoiesis

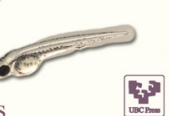

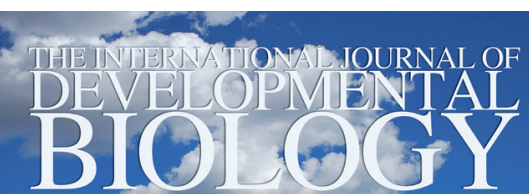

Volume 56 Nos. 10/11/12 - Special Issue

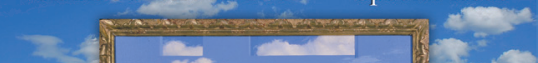

$x+3$

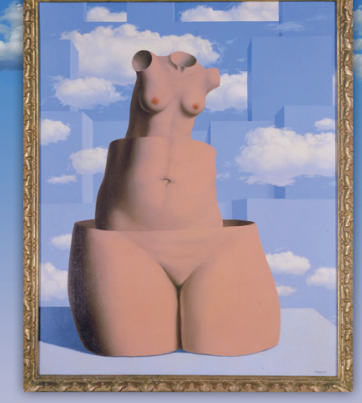

Female Germ Cells in Development \& Tumors
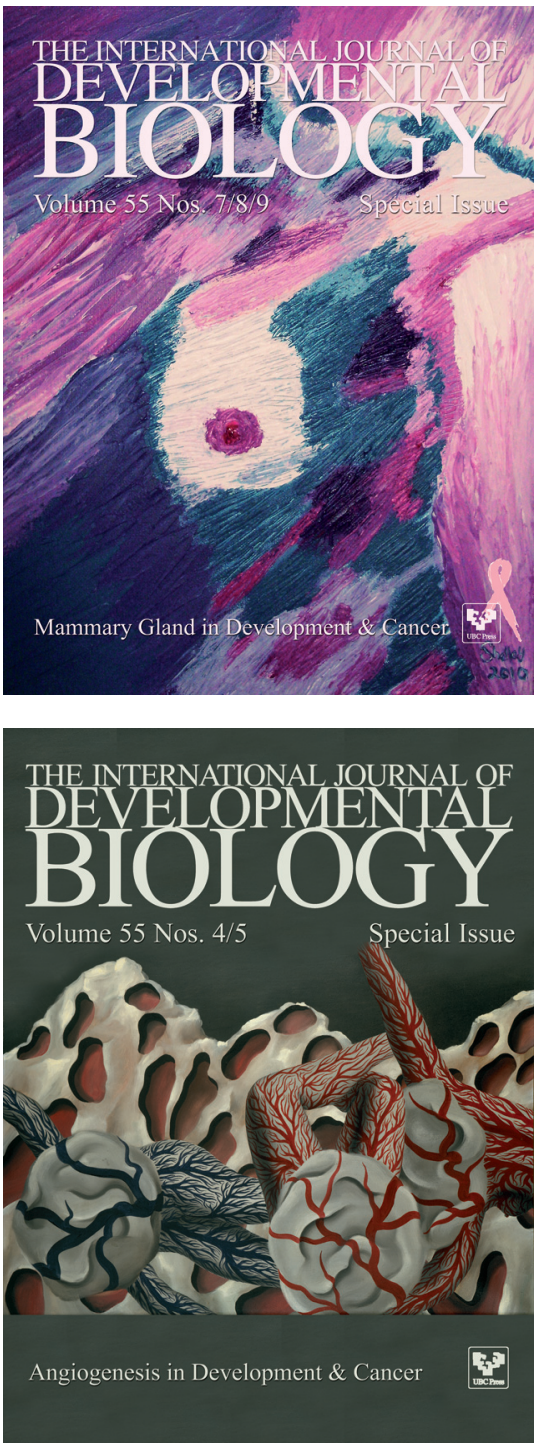